\title{
Pemetaan Kelembagaan dalam Kajian Lingkungan Hidup Strategis DAS Bengawan Solo Hulu
}

\author{
Sri Rum Giyarsih \\ Program Studi Geografi dan Ilmu Lingkungan \\ Fakultas Geografi Universitas Gadjah Mada
}

\begin{abstract}
Abstrak
Fakta empiris memberikan pembuktian terhadap pentingnya pengembangan kelembagaan dalam rangka mencapai keberhasilan suatu program pembangunan, bahkan seringkali program pembangunan yang mengabaikan pengembangan kelembagaan berakhir dengan kegagalan. Pengembangan kelembagaan telah menjadi bagian dari strategi pembangunan tak terkecuali dalam Kajian Lingkungan Hidup Strategis di DAS Bengawan Solo Hulu. Sasaran yang ingin dicapai dari kegiatan pengembangan kelembagaan adalah tumbuhnya kelembagaan yang tangguh, dinamis, dan berdaya saing serta mandiri dalam melakukan pengelolaan lingkungan. Untuk mencapai hal ini maka perlu dilakukan pemetaan kelembagaan di DAS tersebut. Dari pemetaan kelembagaan yang ada di wilayah ini terdapat tiga lembaga yang dapat melakukan kegiatan Koordinasi, Intergrasi, Sinergitas, Sinkronisasi (KISS) yaitu BKPRD (Badan Koordinasi Penataan Ruang Daerah), BP DAS (Badan Pengelolaan Daerah Aliran Sungai)/Forum DAS, dan TKPSDA WS Bengawan Solo (Tim Koordinasi Pengelolaan Sumberdaya Air Wilayah Sungai Bengawan Solo). Di antara ketiga lembaga tersebut maka TKPSDA adalah lembaga yang dipercaya untuk melakukan Koordinasi, Intergrasi, Sinergitas, Sinkronisasi (KISS) dalam pengelolaan lingkungan DAS Bengawan Solo Hulu.
\end{abstract}

Kata kunci: DAS, pemetaan kelembagaan, lingkungan hidup

\section{Pengertian Kelembagaan}

Pengertian lembaga sampai saat ini masih menjadi bahan diskusi yang seru di kalangan ilmuwan sosial. Huntington (1965, dalam Widodo, 2009) mendefinisikan lembaga sebagai pola perilaku yang selalu berulang kokoh dan dihargai oleh masyarakat. Organisasi dan prosedur mempunyai berbagai tingkatan dalam proses pelembagaan. Pelembagaan merupakan sebuah proses di mana organisasi dan prosedur memperoleh nilai dan kemantapan.

Sementara itu Uphoff (1986, dalam Widodo, 2009) memberikan gambaran yang jelas tentang keambiguan antara lembaga dan organisasi. Istilah lembaga dan organisasi secara umum penggunaannya dapat dipertukarkan sehingga menyebabkan kebingungan dan keambiguan di antara keduanya. Namun demikian pakar ini mendefinisikan lembaga sebagai sekumpulan norma dan perilaku yang telah berlangsung dalam waktu yang lama dan digunakan untuk mencapai tujuan bersama.

Lebih jauh Israel (1990, dalam Widodo, 2009) menyatakan bahwa pembedaan antara lembaga dan organisasi masih sangat kabur. Organisasi yang telah mendapatkan kedudukan khusus dan legitimasi dari masyarakat karena keberhasilannya dalam memenuhi kebutuhan dan harapan masyarakat dalam waktu yang panjang dapat dikatakan bahwa organisasi tersebut telah melembaga. 


\section{Kelembagaan Lokal}

Selama ini di level lokal dengan unit administratif desa telah ada seperangkat lembaga-lembaga yang muncul dari inisiatif masyarakat setempat untuk mengelola lingkungan di level desa. Pada umumnya lembaga-lembaga lokal di tingkat desa tersebut masih bersifat tradisional dengan berbagai kekurangan yang ada dari segi kelembagaan modern. Namun demikian di balik kekurangan tersebut, ternyata lembaga-lembaga lokal di tingkat desa telah mampu menelorkan kebijakan-kebijakan dalam rangka untuk mengelola lingkungan menuju sustainable development.

Lemahnya kelembagaan masyarakat desa dalam pengelolaan lingkungan salah satunya disebabkan oleh kurangnya akses masyarakat terhadap informasi pengelolaan lingkungan. Untuk menfasilitasi masyarakat terhadap informasi dalam rangka penguatan kelembagaan, maka perlu adanya upaya penyediaan dan penyebarluasan informasi melalui kegiatan sosialisasi, desiminasi, kampanye, dan penyuluhan. Kegiatan penyediaan dan penyebarluasan informasi dimaksudkan untuk memberikan penjelasan dan pemahaman agar diperoleh persepsi yang sama di antara pihak-pihak terkait.

Dengan penguatan kelembagaan lokal di tingkat desa ini sekaligus ditujukan untuk memberdayakan para pihak terkait di tingkat desa dengan kegiatan pengelolaan lingkungan. Semua ini dilakukan demi terciptanya pranata sosial yang berlaku dalam kehidupan masyarakat lokal di level desa ke arah yang lebih baik dan berkelanjutan melalui pelaksanaan, pengembangan, dan atau pemanfaatan hasil-hasil dan dampak kegiatan pengelolaan lingkungan dalam rangka mensejahterakan masyarakat dan pelestarian lingkungan. Dengan penguatan kelembagaan lokal di tingkat desa ini sekaligus dapat digunakan untuk meningkatkan kemampuan dan kemandirian masyarakat dalam pengelolaan lingkungan serta meningkatkan peran serta dan kepedulian masyarakat dalam pengelolaan lingkungan (Sudarma, 2009).

\section{Pemetaan Kelembagaan di DAS Bengawan Solo Hulu}

Dalam kaitannya dengan Kajian Lingkungan Hidup Strategis DAS Bengawan Solo Hulu, maka dalam berbagai diskusi disepakati bahwa tidak akan membentuk lembaga baru tetapi lebih mengefektifkan peran dan fungsi dari kelembagaan yang sudah ada. Dalam hal ini dari pemetaan kelembagaan yang ada di wilayah ini terdapat tiga lembaga yang dapat melakukan kegiatan Koordinasi, Intergrasi, Sinergitas, Sinkronisasi (KISS) yaitu BKPRD (Badan Koordinasi Penataan Ruang Daerah), BP DAS (Badan Pengelolaan Daerah Aliran Sungai)/Forum DAS, dan TKPSDA WS Bengawan Solo (Tim Koordinasi Pengelolaan Sumberdaya Air Wilayah Sungai Bengawan Solo). 


\section{Badan Koordinasi Penataan Ruang Daerah (BKPRD)}

Badan Koordinasi Penataan Ruang Daerah (BKPRD) beranggotakan beberapa dinas/instansi sektoral yang berkaitan dengan penataan ruang. Badan Koordinasi Penataan Ruang Daerah juga dapat menggunakan tenaga profesional, asosiasi, ataupun perguruan tinggi jika diperlukan. BKPRD ini diketuai oleh Sekretaris Daerah.

Dalam menjalankan tugas pokok dan fungsinya, BKPRD ini mempunyai Kelompok Kerja (Pokja) Perencanaan Pemanfaatan Ruang dan Pokja Pemanfaatan dan Pengendalian Pemanfaatan Ruang. Dalam hal ini BAPPEDA (Badan Perencanan Pembangunan Daerah) berfungsi sebagai leading sector untuk Pokja Perencanaan Pemanfaatan Ruang.

Tugas dari BKPRD adalah mengawal penyusunan dokumen RTRW (Rencana Tata Ruang Wilayah) dan membahas berbagai masalah penataan ruang di daerah. BKPRD menyelenggarakan rapat rutin minimal 3 kali dalam setahun dan hasilnya harus dilaporkan kepada Gubernur dan Menteri Dalam Negeri.

\section{Balai Pengeloaan Daerah Aliran Sungai (BP DAS) dan Forum DAS}

BP DAS (Balai Pengelolaan Daerah Aliran Sungai) merupakan UPT (Unit Pelayanan Teknis) Departemen Kehutanan di daerah. Secara hirarkis BP DAS termasuk dalam eselon 3, sedangkan dinas-dinas sektoral di daerah termasuk dalam eselon 2. Walaupun eselon BP DAS lebih rendah dari pada dinas-dinas sektoral di daerah, namun BP DAS mempunyai wilayah kerja yang lebih luas dari pada dinas-dinas sektoral di daerah. Dalam hal ini BP DAS dapat mengkoordinasi kegiatankegiatan sektor kehutanan di daerah yang melibatkan berbagai dinas sektoral di daerah. Sebagian besar dana pusat untuk sektor kehutanan turunnya juga di BP DAS ini termasuk dana GERHAN (Gerakan Reboisasi Lahan).

Sementara itu Forum DAS dibentuk oleh BP DAS untuk mengkoordinir dinas sektoral dalam rangka untuk pengelolaan DAS agar terjadi integrasi program, pendanaan, pelaksanaan, pengawasan, monitoring dan evaluasi kegiatan yang direncanakan bersama. Dalam pertemuan/rapat untuk pembahasan program ini, Forum DAS biasanya sudah mempunyai daftar kegiatan yang akan dilaksanakan yang menyangkut isu-isu dan permasalahan lingkugan di suatu DAS.

Namun demikian dalam pertemuan dengan dinas sektoral di daerah tersebut, walaupun sudah mempunyai daftar kegiatan BP DAS juga memberi kesempatan kepada dinas sektoral di daerah untuk mengajukan saran maupun program bahkan untuk mengintegrasikan program dinas sektoral dengan program Forum DAS. Contoh integrasi program ini misalnya Dinas Kehutanan mempunyai program Biopori seluas 100 ha dan BP DAS mempunyai program Biopori seluas 150 ha, maka kedua program ini dapat disatukan untuk dikerjakan di suatu wilayah yang sama. 
Tim Koordinasi Pengelolaan Sumber Daya Air Wilayah Sungai Bengawan Solo (TKPSDA WS Bengawan Solo)

Tim Koordinasi Pengelolaan Sumberdaya Air Wilayah Sungai Bengawan Solo (TKPSDA WS Bengawan Solo) merupakan lembaga yang relatif baru pembentukannya. Lembaga ini dibentuk berdasarkan Keputusan Menteri Pekerjaan Umum No.247/KPTS/M/2009 tentang Pembentukan Tim Koordinasi Pengelolaan Sumber Daya Air Wilayah Sungai Bengawan Solo.

Tim Koordinasi Pengeloaan Sumber Daya Air Wilayah Sungai Bengawan Solo beranggotan 64 yag terdiri dari 32 unsur pemerintah dan 32 unsur non pemerintah (TKPSDA WS Bengawan Solo, 2009b). Walaupun TKPSDA WS Bengawan Solo ini dibentuk berdasarkan Keputusan Menteri Pekerjaan Umum namun dalam melaksanakan kegiatannya tidak pernah menggunakan bendera Departemen Pekerjaan Umum ataupun bendera Balai Besar Wilayah Sungai Bengawan Solo sebagai dapur kegiatannya.

\section{Analisis Kelembagaan di DAS Bengawan Solo Hulu}

Setelah memahami tentang peta kelembagaan di wilayah DAS Bengawan Solo Hulu maka selanjutnya dapat dilakukan analisis untuk menentukan lembaga manakah yang akan diangkat untuk melakukan Koordinasi, Intergrasi, Sinergitas, Sinkronisasi (KISS) untuk pengelolaan lingkungan dalam rangka Kajian Lingkungan Hidup Strategis DAS Bengawan Solo Hulu ini. Badan Koordinasi Penataan Ruang Daerah dalam fakta empirisnya kurang aktif dalam kegiataannya. BKPRD biasanya akan berperan aktif pada saat penyusunan dokumen RTRW (Rencana Tata Ruang Wilayah). Sementara itu penyusunan dokumen RTRW itu tidak setiap tahun dilaksanakan. Penyusunan dokumen RTRW baik propinsi maupun kabupaten dilaksanakan setiap 20 tahun sekali dengan peninjauan kembali setiap 5 tahun (Pemerintah RI, 2007). Dengan demikian untuk berperan dalam Koordinasi, Intergrasi, Sinergitas, Sinkronisasi (KISS) untuk pengelolaan lingkungan di DAS Bengawan Solo Hulu nampaknya BKPRD bukanlah lembaga yang tepat.

Secara hirarkis BP DAS termasuk eselon 3 dan dinas sektoral termasuk eselon 2. Dengan demikian kedudukan BP DAS secara hirarkis lebih rendah dari pada dinas sektoral di daerah. Dengan kedudukan yang demikian nampaknya BP DAS juga kurang tepat untuk diangkat sebagai lembaga yang melakukan Koordinasi, Intergrasi, Sinergitas, Sinkronisasi (KISS) untuk pengelolaan lingkungan.

Tim Koordinasi Pengelolaan Sumber Daya Air Wilayah Sungai Bengawan Solo (TKPSDA WS Bengawan Solo) secara hirarkis kedudukannya lebih tinggi dari pada dinas/instansi sektoral karena 
lembaga ini dibentuk berdasarkan kesepakatan bersama antar dinas sektoral di daerah. Walaupun dapurnya di Balai Besar Wilayah Sungai Bengawan Solo yang merupakan bagian dari Departemen Pekerjaan Umum Pusat namun TKPSDA ini tidak pernah menggunakan bendera Departemen Pekerjaan Umum dalam melaksanakan kegiatannya.

Hal ini berbeda dengan BP DAS atau Forum DAS yang selalu menggunakan bendera Departemen Kehutanan dalam melaksanakan kegiatannya. Dengan demikian apabila Tim Koordinasi Pengeloaan Sumber Daya Air Wilayah Sungai Bengawan Solo yang akan diangkat sebagai lembaga yang melakukan Koordinasi, Intergrasi, Sinergitas, Sinkronisasi (KISS) dalam pengelolaan DAS Bengawan Solo Hulu maka harapannya dapat menepis kekuatiran tentang ego sektoral yang mungkin terjadi.

Berdasarkan pertemuan pada tanggal 8 Desember 2009 di Yogyakarta juga telah disepakati bahwa TKPSDA (Tim Koordinasi Pengelolaan Sumber Daya Air) Wilayah Sungai Bengawan Solo adalah lembaga yang akan menfasilitasi seluruh kegiatan dalam rangka Kajian Lingkungan Hidup Strategis DAS Bengawan Solo Hulu. Hal ini berdasarkan pertimbangan-pertimbangan: (1) kerangka kelembagaan dalam TKPSDA wilayah sungai Bengawan Solo, (2) mekanisme formulasi TKPSDA wilayah sungai Bengawan Solo, dan (3) organissi serta keanggotaan TKPSDA wilayah sungai Bengawan Solo.

Menurut TKPSDA WS Bengawan Solo, (2009a), kerangka kelembagaan PKSDA wilayah sungai Bengawan Solo terdiri dari unsur-unsur: (1) regulator (pemerintah pusat/pemerintah daerah), (2) developer (proyek pemerintah dan swasta), (3) operator (balai, PJT, private), dan (4) user (petani, industri, dan PDAM). Sementara itu mekanisme pembentukan TKPSDA wilayah sungai Bengawan Solo dimulai dari menteri/gubernur/bupati/walikota yang menetapkan tim persiapan pemilihan yang beranggotakan: (1) instansi yang membidangi sumberdaya air, (2) Dinas Kehutanan, (3) Dinas Lingkungan Hidup, (4) Dinas Pertanian, (5) sekretariat daerah, dan (6) BBWS/BWS yang bersangutan. TKPSDA sendiri terdiri dari unsur pemerintah dan non pemerintah. Dalam TKPSDA Wilayah Sungai Bengawan Solo juga telah terbentuk tiga komisi yaitu: (1) komisi konservasi sumberdaya air, (2) komisi pendayagunaan sumberdaya air, dan (3) komisi pengendalian daya rusak air. Adapun tugas dari TKPSDA Wilayah Sungai Bengawan Solo adalah:

(1) Pembahasan rancangan pola dan rancangan rencana pengelolaan sumberdaya air wilayah sungai,

(2) Pembahasan rancangan rencana pengelolaan sumberdaya air wilayah sungai, rancangan rencana program dan rencana kegiatan pengelolaan sumberdaya air yang disusun secara terpadu 
berdasarkan strategi pengelolaan sumberdaya air yang dipilih dari alternatif strategi yang terdapat dalam pola pengelolaan sumberdaya air,

(3) Pembahasan rancangan program dan kegiatan pengelolaan sumberdaya air wilayah,

(4) Pembahasan usulan rencana alokasi air dari setiap sumber air pada wilayah sungai lintas provinsi,

(5) Pembahasan rancangan sistem hidrologi, hidrometerologi, dan hidrogeologi agar tercapai keterpaduan sistem informasi sumberdaya air.

Sementara itu tugas masing-masing komisi disajikan pada Tabel 1.

Tabel 1. Tugas Per Komisi Dalam TKPSDA WS Bengawan Solo

\begin{tabular}{|c|c|}
\hline Komisi & Tugas \\
\hline \multirow[t]{5}{*}{ Konservasi Sumberdaya Air } & Konservasi DAS \\
\hline & Konservasi SDA \\
\hline & Konservasi sempadan \\
\hline & Perlindungan dan pelestarian sumber air \\
\hline & Pengelolaan kualitas air \\
\hline \multirow[t]{7}{*}{ Pendayagunaan Sumberdaya Air } & Penatgunaan air \\
\hline & Pembagian air \\
\hline & Pengembangan SDA \\
\hline & Pengelolaan air \\
\hline & Pengusahaan SDA \\
\hline & Penyediaan SDA \\
\hline & Penggunaan SDA \\
\hline \multirow[t]{4}{*}{ Pengendalian Daya Rusak } & Pencegahan sebelum bencana \\
\hline & Early warning \\
\hline & Pengendalian banjir dan kekeringan \\
\hline & Pemulihan akibat banjir dan kekeringan \\
\hline Komisi & Tugas \\
\hline \multirow[t]{5}{*}{ Konservasi Sumberdaya Air } & Konservasi DAS \\
\hline & Konservasi SDA \\
\hline & Konservasi sempadan \\
\hline & Perlindungan dan pelestarian sumber air \\
\hline & Pengelolaan kualitas air \\
\hline \multirow[t]{7}{*}{ Pendayagunaan Sumberdaya Air } & Penatgunaan air \\
\hline & Pembagian air \\
\hline & Pengembangan SDA \\
\hline & Pengelolaan air \\
\hline & Pengusahaan SDA \\
\hline & Penyediaan SDA \\
\hline & Penggunaan SDA \\
\hline \multirow[t]{4}{*}{ Pengendalian Daya Rusak } & Pencegahan sebelum bencana \\
\hline & Early warning \\
\hline & Pengendalian banjir dan kekeringan \\
\hline & Pemulihan akibat banjir dan kekeringan \\
\hline
\end{tabular}

Sumber: TKPSDA WS Bengawan Solo, $2009 a$. 


\section{Kesimpulan}

Dari hasil pemetaan dan analisis kelembagaan selanjutnya dapat ditarik kesimpulan bahwa terdapat tiga lembaga yang memungkinkan untuk pengelolaan DAS Bengawan Solo Hulu yaitu BKPRD, BP DAS/Forum DAS, dan TKPSDA. Di antara ketiga lembaga tersebut maka TKPSDA adalah lembaga yang dipercaya untuk melakukan Koordinasi, Intergrasi, Sinergitas, Sinkronisasi (KISS) dalam pengelolaan lingkungan DAS Bengawan Solo Hulu.

\section{Daftar Pustaka}

Pemerintah RI. (2007). Undang-Undang No 26 Tahun 2007 tentang Penataan Ruang. Sinar Grafika. Jakarta.

Sudarma, Anang. (2009). Penguatan Kelembagaan Masyarakat Desa dan KTH Dalam Pembangunan RHL dalam Prosiding Dialog Stakeholder Kegiatan Rehabilitasi Lahan Kritis Berbasis Pemberdayaan Masyarakat Pedesaan di Kabupaten Ciamis.

TKPSDA WS Bengawan Solo. (2009a). News Letter Edisi Perdana Februari 2009. Surakarta.

TKPSDA WS Bengawan Solo. (2009b). News Letter Edisi 04 September 2009. Surakarta.

Widodo, Slamet. (2009). Kelembagaan, Kapital Sosial, dan Pembangunan dalam http://learningof.slametwidodo.com (diunduh tanggal 14 Desember 2009). 